\title{
Validity and reliability of the Indonesian version of the Chronic Urticaria Quality of Life Questionnaire (CU- $\left.Q_{2} \mathrm{oL}\right)$
}

\author{
Teffy Nuary, ${ }^{1}$ Windy Keumala Budianti, ${ }^{1}$ Wresti Indriatmi, ${ }^{1}$ Ilaria Baiardini ${ }^{2}$
}

\begin{abstract}
Background: Assessment of quality of life is needed to assess therapeutic response. There is currently no instrument available for assessing the quality of life of chronic urticaria patients in Indonesia. CU- $\mathrm{Q}_{2} \mathrm{OL}$ is a specific questionnaire for chronic urticaria that was first developed in Italian. Validity and reliability tests are important to ensure that the language or term used are appropriate to the local culture and there is no change in the validity and reliability of the questionnaire.
\end{abstract}

Objective: The aim of this study is to develop an Indonesian version of CU- $\mathrm{Q}_{2} \mathrm{oL}$.

Methods: The Italian version $\mathrm{CU}-\mathrm{Q}_{2} \mathrm{oL}$ was translated into Indonesian and underwent cross-cultural adaptation. The translated questionnaire was completed online by 40 chronic urticaria patients of the Dermatovenereology Outpatient Clinic of the Cipto Mangunkusumo General Hospital, Jakarta, Indonesia.

Results: Validity test resulted in correlation coefficient values for all questions of 0.467 to 0.856 . Reliability test showed a Cronbach's $\alpha$ coefficient of all questions of 0.923 and the intraclass correlation coefficient (ICC) for all questions was 0.913 .

Conclusion: This study demonstrates that the Indonesian $\mathrm{CU}-\mathrm{Q}_{2} \mathrm{oL}$ questionnaire is valid, reliable, and suitable to assess the quality of life of chronic urticaria patients in Indonesia.

Key words: Chronic Urticaria, CU-Q 2 oL, Validation, Reliability, Quality of Life

From:

${ }^{1}$ Department of Dermatology and Venereology, Faculty of Medicine,

Universitas Indonesia - dr. Cipto Mangunkusumo General Hospital, Jakarta, Indonesia

2 Department of Biomedical Sciences, Humanitas University, Milan, Italy

\section{Introduction}

Chronic urticaria is a skin disorder which clinically manifests as wheals lasting more than 6 weeks, and may be accompanied by angioedema. The lesions appear suddenly and usually resolves within 30 minutes to 24 hours without any residual lesions. Subjective symptoms include itching, burning, and stinging sensations on the skin. ${ }^{1,2}$

The global prevalence of chronic urticaria affects around $0.5 \%$ to $5 \%$ of the population, with an annual incidence of $1.4 \% .{ }^{3,4}$ Chronic inducible urticaria (CIndU) makes up roughly $20-30 \%$ of chronic urticaria cases. ${ }^{5}$ In 2018 , chronic urticaria is the first leading cause of outpatient patient visits in the Allergy-Immunology Division of the Dermatovenereology Clinic, Cipto Mangunkusumo General Hospital, Jakarta,
Corresponding author:

Wresti Indriatmi

Jl. Diponegoro no.71, Jakarta 10430, Indonesia

E-mail: dr.teffynuary@gmail.com

Indonesia. Most of the urticaria patients are women, aged 1668 years old.

The effects of chronic urticaria on the patient's life, the lives of their family, their social life, and the healthcare system cannot be underestimated. In addition to clinical symptoms, there is considerable negative impact on the patient's quality of life due to urticaria. ${ }^{2}$ A study by O'Donell et $\mathrm{al}^{6}$ described the quality of life of patients with chronic urticaria is comparable to patients with coronary heart disease. Health status and subjective satisfaction of patients with chronic spontaneous urticaria (CSU) are worse than patients with respiratory allergies. ${ }^{2}$ Therefore, an instrument to assess patients' quality of life is needed to determine the disease's impact 
on the patient's wellbeing. To date, no instrument in Indonesian is available to assess the quality of life of chronic urticaria patients.

The Chronic Urticaria Quality of Life Questionnaire (CU$\mathrm{Q}_{2} \mathrm{OL}$ ) is the only specific questionnaire for chronic urticaria, developed in 2005 in Italian by Prof Ilaria Baiardini, as a simple, understandable questionnaire that can be filled out by the patient independently. This questionnaire aims to evaluate the impact of chronic urticaria from the patients' perspective, contain 23 questions of six aspects. ${ }^{7}$ The European Academy of Allergy and Clinical Immunology (EAACI), the Global Allergy and Asthma European Network (GA2LEN), the European Dermatology Forum (EDF), and the World Allergy Organization (WAO) have accepted CU- $\mathrm{Q}_{2} \mathrm{OL}$ as a mandatory assessment for chronic urticaria patients. ${ }^{2,8}$ In order to be used in other languages, cross-cultural adaptation need to be performed, to ensure comparable results to the original questionnaire. Validity and reliability tests are important to ensure the language used can be easily understood by patients in the community and to ensure the validity and reliability of the original questionnaire are not compromised. ${ }^{9}$ The aim of the present study was to adapt and validate the CU- $\mathrm{Q}_{2} \mathrm{OL}$ to assess the quality of life of chronic urticaria patients in Indonesia.

\section{Methods}

This was a cross-sectional study on patients with chronic urticaria who visited the Dermatovenereology Clinic of the Cipto Mangunkusumo General Hospital, Jakarta, a tertiary referral hospital in Indonesia, from January to July 2020. Patients were invited to participate in this study by consecutive sampling. We included chronic urticaria patients aged over 18 years old who provided written consents and excluded patients with poorly controlled comorbidities.

\section{Translation and cross-cultural adaptation of the question- naire}

Consent to translate the questionnaire to Indonesian was obtained from the original authors. Translation was performed from Italian to Indonesian by two professional translators from the Institutio Italiano di Cultura (IIC) Jakarta, who were fluent in both Italian and Indonesian. Each of the translators produced a translated questionnaire. Experts in patients' quality of life and physicians specializing in allergy discussed the two versions and synthesized them to create an Indonesian version of the questionnaire. Ethical approval was given by the ethical committee of Universitas Indonesia and Cipto Mangunkusumo General Hospital's Institutional Review Board.

The questionnaire was translated back to Italian by a professional translator from IIC, who was an Italian citizen fluent in Indonesian. The translator was not aware of the original version of the questionnaire. The results and any accompanying comments were sent to Prof Ilaria Baiardini to be reviewed. The re-translation results were compared to the original questionnaire to inspect if any inconsistencies were present.
After the original author of the questionnaire approved the translated version, the pre-final questionnaire was tested on 10 chronic urticaria patients. The subjects filled in the questionnaire on Google Forms, and they were interviewed afterwards to explore if the questionnaire was easy to understand and if any changes should be made. Due to the COVID-19 pandemic, history-taking, physical examination, informed consent process, and interviews regarding the questionnaire were done through telemedicine.

\section{Validity and reliability test of the translated questionnaire}

The final phase of the study was the validity and reliability test on 30 subjects. The validity test was performed by subjects and a board of experts, including experts on dermatovenereology, allergy and immunology, quality of life of allergy and immunology patients, and methodology.

Subjects and the board of experts discussed and provided critique of the questionnaire. Construct validity was assessed by calculating the correlation of each question with the total score using Pearson product moment correlation coefficients. A score of $<0.3$ was interpreted as an invalid questionnaire.

Reliability tests included tests for internal consistency and for test-retest reliability. Internal consistency was tested by using Cronbach's alpha ( $\alpha$ ) coefficient, where $\alpha>0.7-0.8$ was considered acceptable, $\alpha>0.8$ was considered good, and $\alpha>$ 0.9 was considered very good. Test-retest reliability was assessed using the intra-class correlation coefficient (ICC); ICC results were categorized as follows: $<0.50$ weak correlation, 0.50-0.75 moderate correlation, 0.75-0.90 good correlation, > 0.90 excellent correlation. The test-retest assessment was performed one week after the questionnaires were completed, by patients whose Urticaria Activity Score over 7 Days (UAS7) was stable (no changes in degree of disease activity, interval of score changes $0-4)$. Data were analyzed using SPSS version 20.0 .

\section{Results}

The age range of the subjects was 23-47 years old. The lowest education level of the subjects was primary school (one subject), and the highest was bachelor's degree (4 subjects). The baseline characteristics of study subjects are shown in Table 1. The questionnaire was tested on 10 subjects, who were Indonesian native speakers. The average time needed to complete the questionnaire was 5.7 minutes, with a fastest time of 4 minutes and longest of 7 minutes. In this phase, there were no difficulties in understanding the questionnaire.

Originally, 30 subjects were recruited for the second phase of the study (validity and reliability test). Due to lack of difficulties in completing the questionnaire and no changes were made to the questionnaire in the first phase of the study, the 10 subjects of the first phase continued their participation to the second phase, resulting in 40 subjects participating in the second phase.

Validity tests included testing for content validity and construct validity. The results of the validity tests are shown in Table 2. Reliability tests include internal consistency and test-retest. Cronbach's a was used for internal consistency. 
Table 1. Sociodemographic and clinical characteristics of study subjects.

\begin{tabular}{|c|c|c|}
\hline Characteristic & $\begin{array}{l}\text { First phase, } \\
\qquad \begin{array}{c}(\mathbf{N}=10) \\
n(\%)\end{array}\end{array}$ & $\begin{array}{l}\text { Second phase, } \\
\begin{array}{c}(\mathbf{N}=40) \\
\text { n }(\%)\end{array}\end{array}$ \\
\hline \multicolumn{3}{|l|}{ Sex } \\
\hline Male & $2(20)$ & $9(22.5)$ \\
\hline Female & $8(80)$ & $31(77.5)$ \\
\hline Age, years mean (SD) & $35.9(10.1)$ & $33.7(8.6)$ \\
\hline \multicolumn{3}{|l|}{ Marital status } \\
\hline Single & $3(30)$ & $14(35)$ \\
\hline Married & $7(70)$ & $24(60)$ \\
\hline Divorced & - & $2(5)$ \\
\hline \multicolumn{3}{|l|}{ Education level } \\
\hline Primary school & $1(10)$ & $1(2.5)$ \\
\hline High school & $3(30)$ & $15(37.5)$ \\
\hline Diploma & $2(20)$ & $7(17.5)$ \\
\hline Bachelor's degree & $4(40)$ & $15(37.5)$ \\
\hline Master's degree & - & $1(2.5)$ \\
\hline \multicolumn{3}{|l|}{ Occupation } \\
\hline Homemaker & $2(20)$ & $9(22.5)$ \\
\hline Private employee & $3(30)$ & $13(32.5)$ \\
\hline Civil servants & $2(20)$ & $4(10)$ \\
\hline Entrepreneur & - & $1(2.5)$ \\
\hline Student & - & $4(10)$ \\
\hline Others & $3(30)$ & $9(22.5)$ \\
\hline
\end{tabular}

Ethnic group

\begin{tabular}{lcc} 
Betawi & $2(20)$ & $3(7.5)$ \\
Javanese & $5(50)$ & $13(32.5)$ \\
Sundanese & $2(20)$ & $9(22.5)$ \\
Minang & $1(10)$ & $6(15)$ \\
Chinese-Indonesian & - & $3(7.5)$ \\
Batak & - & $4(10)$ \\
Balinese & - & $1(2.5)$ \\
Manado & - & $1(2.5)$ \\
UAS 7, scores mean (SD) & $12(8.1)$ & $15.4(6.6)$ \\
Duration of disease, years mean (SD) & $3.7(2.6)$ & $3.9(3.1)$ \\
\hline
\end{tabular}

Table 2. Distribution of Pearson's correlation coefficients of each question with the topic score and total score of the translated $\mathrm{CU}-\mathrm{Q}_{2} \mathrm{oL}$ questionnaire

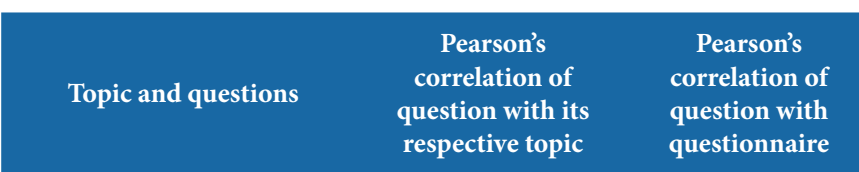

Itching

$\begin{array}{lcc}\text { - Pruritus } & 0.923 & 0.623 \\ \text { - Wheals } & 0.903 & 0.691\end{array}$

Swelling

$\begin{array}{lll}\text { - Eyes swelling } & 0.958 & 0.641 \\ \text { - Lips swelling } & 0.952 & 0.538\end{array}$

Daily activities

$\begin{array}{lcc}\text { - Work } & 0.860 & 0.856 \\ \text { - Physical activities } & 0.850 & 0.710 \\ \text { - Sleep } & 0.585 & 0.505 \\ \text { - Free time } & 0.838 & 0.701 \\ \text { - Social relationship } & 0.811 & 0.661 \\ \text { - Eating } & 0.769 & 0.745\end{array}$

Sleep problems

$\begin{array}{lcc}\text { - Falling asleep } & 0.819 & 0.739 \\ \text { - Waking up at night } & 0.773 & 0.674 \\ \text { - Tired } & 0.782 & 0.586 \\ \text { - Concentration } & 0.694 & 0.640 \\ \text { - Nervousness } & 0.624 & 0.507\end{array}$

Disability

$\begin{array}{lcc}\text { - Bad mood } & 0.912 & 0.467 \\ \text { - Limit food } & 0.850 & 0.568 \\ \text { - Sports } & 0.714 & 0.468\end{array}$

\begin{tabular}{lcc} 
Appearances & & \\
- Embarassed by signs & 0.827 & 0.775 \\
- Embarassed in public & 0.718 & 0.490 \\
- Cosmetic & 0.653 & 0.480 \\
- Limits clothes & 0.675 & 0.451 \\
- Medication side - effects & 0.619 & 0.503 \\
\hline
\end{tabular}

Note: valid if Pearson's correlation coefficient $>0.3$ 
Table 3. Cronbach's $\alpha$ and intraclass correlation coefficients of the translated questionnaire.

\begin{tabular}{|c|c|c|}
\hline & $\begin{array}{l}\text { Cronbach's } \alpha \\
\text { coefficient }\end{array}$ & $\begin{array}{l}\text { Intraclass correlation } \\
\text { coefficient }(n=23)\end{array}$ \\
\hline Entire questionnaire & 0.923 & 0.913 \\
\hline \multicolumn{3}{|l|}{ Topic } \\
\hline - Itching & 0.801 & 0.926 \\
\hline - Swelling & 0.904 & 0.944 \\
\hline - Daily activities & 0.876 & 0.913 \\
\hline - Sleep problems & 0.792 & 0.898 \\
\hline - Disabilities & 0.767 & 0.943 \\
\hline - Appearances & 0.738 & 0.950 \\
\hline
\end{tabular}

The Cronbach's a coefficient for the questionnaire was 0.923, and the coefficient for each topic ranged from $0.738-0.904$. ICC coefficients from test-retest reliability assessment was 0.913 for the entire questionnaire, and 0.898-0.950 for each question. The results of the reliability test are shown in Table 3.

\section{Discussion}

This study has shown that Indonesian version of $\mathrm{CU}-\mathrm{Q}_{2} \mathrm{OL}$ is a reliable and valid instrument for use in patients with $\mathrm{CU}$ and can be considered semantically equivalent to the original instrument. The translation results were synthesized and discussed by a board of experts to ensure the language was easily understandable for chronic urticaria patients with different backgrounds. In the pre final phase 10 subjects with a variation of age, sex, ethnic group, and education level subjects stated the questionnaire was easy to understand and no difficulties were found when completing the questionnaire, thus no changes were needed. The number of study subjects in this phase was determined according to cross-cultural adaptation guidelines made by the authors of the original questionnaire, which stated a minimal 10 respondents were needed for the pre-final phase. This phase aimed to assess whether the translated questionnaire was understandable, concise, and appropriate.

Next, validity and reliability tests were performed with 40 subjects. Our study found Indonesian version of the CU$\mathrm{Q}_{2} \mathrm{OL}$ to be a valid questionnaire to assess the quality of life of chronic urticaria patients in Indonesia. Our data was consistent with validity tests of the Italian, Brazilian, Thai, German, Turkish, and Spanish versions of CU-Q $20 L .^{7,8,10,11}$ The interface and ease-of-use of the questionnaire were also considered; we used Google Form to enable easy access to the questionnaire online. Questionnaires that are accessible and inviting will increase respondent's enthusiasm to complete them. ${ }^{12}$

Reliability test for internal consistency was performed by calculating Cronbach's a coefficient. The Cronbach's a coeffiicient for the entire questionnaire was 0.923 , interpreted as very good reliability. Our results were in line with Dias et al's ${ }^{13}$ Brazilian-Portuguese version of $\mathrm{CU}-\mathrm{Q}_{2} \mathrm{OL}$, where the Cronbach's a coefficient for the translated questionnaire was 0.93 .
The internal consistency of the questions within each topic showed this instrument had good to very good internal consistency, agreeing with the internal consistency of the original questionnaire. $^{7}$

The next reliability test was for the test-retest reliability. Subjects who had stable UAS7 scores were asked to re-complete the questionnaire 1 week after the first completion. We decided on 7 days between questionnaires to minimize the any changes in the patient's condition because clinical symptoms of urticaria can fluctuate. ${ }^{14}$ Of all subjects, 23 were selected to participate in the test-retest because of their stable UAS7 scores. ICC of the first and second questionnaire completion were calculated. We found excellent correlation (ICC $=0.913$ ) for the questionnaire, and ICC of $0.855-0.90$ for each of the topics. Excellent ICC shows that the translated questionnaire is consistent and can be used repeatedly on patients with similar conditions. Test-retest reliability test was also performed by Kulthanan et $\mathrm{al}^{8}$ who arranged a 2 -weeks interval between questionnaires and obtained an ICC of 0.76 . Dias et al's ${ }^{13}$ test-retest resulted in excellent correlation, with an ICC of 0.78 .

\section{Conclusion}

We adapted a questionnaire on the quality of life of chronic urticaria patients through cross-cultural adaptation and translation to be used as a clinical instrument in Indonesia. The Indonesian version of $\mathrm{CU}-\mathrm{Q}_{2} \mathrm{OL}$ is valid and reliable.

\section{Acknowledgement}

The study was funded by Universitas Indonesia's 2020 International Publication in Science, Technology, and Medicine Grant.

\section{References}

1. Michihiro H, Shunsuke T, Takaaki H. Urticaria and Angioedema. In: Sewon K, Masayuki A, Anna L B, Alexander H E, David J M, Amy J MM, et al., editor. Fitzpatrick's Dermatology. 9th ed. New York: McGraw-Hill Education; 2019. p. 685-704.

2. Asero WAR, Baker AHALD, Bernstein BBJA, Bedrikow RB, Danilycheva I V, Godse K, et al. The EAACI / GA 2 LEN / EDF / WAO guideline for the definition, classification, diagnosis and management of urticaria. Allergy. 2018;73:1393-414.

3. Schaefer P, College T, Sciences L. Acute and chronic urticaria: Evaluation and treatment. Am Fam Physician. 2017;95(11):717-24.

4. Bernstein JA, Lang DM, Khan DA, Contributors W, Craig T, Dreyfus $\mathrm{D}$, et al. Practice parameter the diagnosis and management of acute and chronic urticaria : 2014 update Department of Internal Medicine. J Allergy Clin Immunol. 2014;133(5):1270-7.

5. Darlenski R, Kazandjieva J, Zuberbier T, Tsankov N. Chronic urticaria as a systemic disease. Clin Dermatol. 2014;32(3):420-3.

6. Rlawlor BFOD, Simpson J, Morgan M, Greaves MW. The impact of chronic urticaria on the quality of life. Br J Dermatol. 1997;136:197-202.

7. Baiardini I, Pasquali M, Braido F, Fumagalli F, Guerra L, Compalati E, et al. A new tool to evaluate the impact of chronic urticaria on quality of life : Chronic urticaria quality of life questionnaire ( CU- $\mathrm{Q}_{2} \mathrm{oL}$ ). 2005;(5): 1073-8.

8. Kulthanan K, Chularojanamontri L, Tuchinda P, Rujitharanawong C, Baiardini I, Braido F. Original article minimal clinical important difference ( MCID ) of the Thai chronic urticaria quality of life questionnaire. Asian Pac J Allergy Immunol. 2016;34:137-45.

9. Beaton DE, Bombardier C, Guillemin F, Ferraz MB. Guidelines for the Process of Cross-Cultural Adaptation of Self-Report Measures. Spine (Phila Pa 1976). 2000;25(24):3186-91. 
10. Erdem T, Kocatürk E, Utkan K, Can P, Oztas R, Gelincik A, et al. Validation of the Turkish version of the urticaria control test: Correlation with other tools and comparison between spontaneous and inducible chronic urticaria. World Allergy Organ J. 2019;12:1-8.

11. Kessel A, Graif Y, Vadasz Z, Schichter-Konfino V, Almog M, Cohen S, et al. Adaptation and validation of the Israeli version of the Chronic Urticaria Quality of Life Questionnaire (Cu- $\left.\mathrm{Q}_{2} \mathrm{OL}\right)$. Isr Med Assoc J. 2016;18(8): 461-5.
12. Ancok D. Validitas dan reliabilitas instrumen penelitian [Validity and reliability of research instruments]. In: Effendi ST, editor. Metode penelitian survei [Methods of survey studies]. Jakarta: LP3ES; 2012. p.124-47. Indonesian.

13. Papi JA, Jr SDD, Levy SAP. Cross-cultural adaptation of the Brazilian - Portuguese version of the chronic urticaria quality-of-life questionnaire - CU-Q_oL. Eur J Allergy Clin Immunol. 2011;66(11):1487-93.

14. Azwar S. Reliabilitas dan Validitas [Reliability and Validity]. Yogyakarta: Pustaka Pelajar; 2015. Indonesian. 